\title{
Correlation between thyroglobulin gene polymorphisms and autoimmune thyroid disease
}

\author{
LI-QIANG WANG ${ }^{1,2}$, TIAN-YUN WANG ${ }^{1}$, QIU-LI SUN ${ }^{1}$ and YONG-QIANG QIE ${ }^{2}$ \\ ${ }^{1}$ Department of Biochemistry and Molecular Biology, Xinxiang Medical University, Xinxiang, Henan 453003; \\ ${ }^{2}$ Department of Nuclear Medicine, Anyang Regional Hospital of Puyang City, Anyang, Henan 455000, P.R. China
}

Received September 11, 2014; Accepted May 19, 2015

DOI: $10.3892 / \mathrm{mmr} .2015 .3978$

\begin{abstract}
The aim of the present study was to detect thyroglobulin $(\mathrm{Tg})$ gene polymorphisms in a Han Chinese population from the Northern regions of Henan province, China, and to study the correlation between Tg gene polymorphisms and autoimmune thyroid disease (AITD). A total of 270 patients with AITD and 135 healthy controls were enrolled. Genomic DNA was extracted and fluorescence polymerase chain reaction analysis was performed; high-resolution melting curve analysis (HRMA) was used to detect single-nucleotide polymorphisms (SNPs) in exons 10,12 and 33 of the Tg gene. SNPs were then correlated with AITD. Han people from the Northern regions of Henan displayed four Tg exon SNPs: E10SNP24 T/G, E10SNP158 T/C, E12SNP A/G and E33SNP C/T. Several allele and genotype frequencies differed between the AITD group and the healthy control group (Tg E10SNP: Allele T, P $<0.01$; allele G, $\mathrm{P}<0.01$; and Tg genotype GG, $\mathrm{P}<0.01$; genotype TG, $\mathrm{P}<0.01$. Tg E12SNP: Allele A, $\mathrm{P}<0.01$; allele $\mathrm{G}, \mathrm{P}<0.01$; Tg genotype GG, $\mathrm{P}<0.01$; genotype AG, $\mathrm{P}<0.01)$. A statistically significant difference in the frequency of selected Tg SNPs haplotypes was also present between AITD patients and healthy controls $(\mathrm{P}<0.05)$. There was no significant difference in haplotypes between various types of AITD (hypothyroidism, hyperthyroidism and Hashimoto's disease). The Tg SNP frequency distribution was significantly different between Han populations of the Northern regions of Henan province and the Xi'an regions of Shaanxi province. The results of the present study suggested that specific $\mathrm{Tg}$ gene alleles or genotypes were correlated with AITD; specific Tg SNP haplotypes were associated with hypothyroidism, hyperthyroidism and Hashimoto's disease, and the Tg SNP frequency distribution
\end{abstract}

Correspondence to: Dr Tian-Yun Wang, Department of Biochemistry and Molecular Biology, Xinxiang Medical University, 601 Jinsui Road, Xinxiang, Henan 453003, P.R China

E-mail: wtianyuncn@126.com

Key words: high-resolution melting curve assay, autoimmune thyroid disease, thyroglobulin, single nucleotide polymorphism differed depending on the geographical location of the Han Chinese populations.

\section{Introduction}

Autoimmune thyroid disease (AITD) encompasses a range of thyroid conditions, including hyperthyroidism (Graves' disease), Hashimoto's disease (Hashimoto's thyroiditis), idiopathic myxedema and primary hypothyroidism. Genetic factors have an important role in the occurrence of AITD (1). Genetic screening has shown that susceptibility genes for AITD include human leukocyte antigen and the cytotoxic T-lymphocyte-associated antigen-4 (2). Although AITD has been associated with immunomodulatory genes, this does not fully explain the specific autoimmune attack directed towards the thyroid. Therefore, disease-associated antigen-specific genes, including those encoding thyroid peroxidase, thyroid-stimulating hormone receptor and thyroglobulin $(\mathrm{Tg})$ comprise another group of candidate genes which are potentially associated with AITD (2). To date, only few studies on $\mathrm{Tg}$ and genes associated with the susceptibility to AITD have been performed, and the findings from different population are not consistent (3-5), possibly due to a range of different detection methods used. Commonly used methods for analyzing differences in gene sequences include single-strand conformation polymorphism (6), denaturing gradient gel electrophoresis (7), denaturing high-performance liquid chromatography (8), temperature gradient capillary electrophoresis (9) and mass spectrometry (10). These methods require separate samples, enzymatic reactions and chemical reactions; these methods are complex, comprise multiple steps, and are time-consuming and challenging to perform. However, the high-resolution melting curve analysis (HRMA) method is relatively simple, fast, accurate, economical and suitable for high-throughput analysis (11-14). HRMA can effectively distinguish between different alleles and genotypes at single nucleotide polymorphism (SNP) loci $(13,15,16)$. To date, three novel methods have been developed for HRMA: The small-fragment amplification method (17), the non-labeled probe method (18) and the snapback probe primer method (19). A recent study showed that the method of genomic DNA extraction influences the polymerase chain reaction (PCR)-HRMA product (20). HRMA has previously been used to detect variable-number 
Table I. PCR primers used in the present study.

\begin{tabular}{|c|c|c|}
\hline Name & Sequence & PCR product length (bp) \\
\hline \multicolumn{3}{|l|}{ HRM } \\
\hline E10SNP24 & $\begin{array}{l}\text { F: 5'-CACCTGCTCATTGTTCCTCC-3' } \\
\text { R: 5'-GGCCTGCACCGTCCTGAG-3' }\end{array}$ & 80 \\
\hline E10SNP158 & $\begin{array}{l}\text { F: 5'-CTACATCCCACAGTGCAGC-3' } \\
\text { R: 5'-CGTTGGTACAACTCGAAGAC-3' }\end{array}$ & 87 \\
\hline E12SNP & $\begin{array}{l}\text { F: 5'-CGACTCGGCTGGAGCATC-3' } \\
\text { R: 5'-GCGTGGCACTGCACAGGC-3' }\end{array}$ & 93 \\
\hline E33SNP & $\begin{array}{l}\text { F: 5'-ACCTTCAGGCCTGCTCTTTC-3' } \\
\text { R: 5'-AGTGCAGCATGGGTCCGC-3' }\end{array}$ & 80 \\
\hline \multicolumn{3}{|l|}{ Sequencing } \\
\hline E10SNP & $\begin{array}{l}\text { F: 5'-GCTGATCACCAACTGATGTC-3' } \\
\text { R: 5'-CTGAAGTTTCCGGAAGCTGC-3' }\end{array}$ & 481 \\
\hline E12SNP & $\begin{array}{l}\text { F: 5'-CATACGTGGTTGTTCTCAGC-3' } \\
\text { R: 5'-GCTCCTGTTACACAAGTGAG-3' }\end{array}$ & 389 \\
\hline E33SNP & $\begin{array}{l}\text { F: 5'-GGACAGTATTCCTGAGAGGAG-3' } \\
\text { R: 5'-GAACGAGGATAGGAGATGCTG-3' }\end{array}$ & 403 \\
\hline
\end{tabular}

PCR, polymerase chain reaction; HRM, high-resolution melting curve assay; SNP, single nucleotide polymorphism; E10, exon 10; F, forward; $\mathrm{R}$, reverse.

tandem repeats and displayed consistency with traditional gel electrophoresis (21), a technique which is widely used in genetic testing. To utilize this technique, the present study adopted a protocol for the preparation and use of reagents to extract DNA (22). In the present study, HRMA amplification of small fragments was employed to study $\mathrm{Tg}$ gene polymorphisms of a Han Chinese population from the Northern regions of Henan province and examined the correlation between $\mathrm{Tg}$ gene polymorphisms and AITD.

\section{Materials and methods}

Clinical data. A total of 270 AITD patients (180 females, 90 males) were enrolled at the Department of Nuclear Medicine, Anyang Regional Hospital (Anyang, China) between February 2013 and January 2014. The average age of female and male AITD patients was $37.72 \pm 14.30$ and $38.04 \pm 12.77$ years, respectively. A control group comprising 135 healthy individuals ( 90 females and 45 males) was recruited at Anyang Regional Hospital Medical Center (Anyang, China). The average age of female and male control subjects was $35.68 \pm 11.67$ and $38.16 \pm 11.75$ years, respectively. The inclusion criteria were as follows: The diagnosis of AITD was based on typical clinical symptoms, and was confirmed by laboratory tests (90 cases of primary hypothyroidism, 90 cases of Graves' disease and 90 cases of Hashimoto disease) (23). The control group was age- and gender-matched with the AITD group. The study was approved by the Ethics Committee of Anyang Regional Hospital of Puyang (Puyang, China). Written informed consent was obtained from the patient.

Genomic DNA extraction from blood. Genomic DNA extraction was performed according to the method of Wang et al (22). First, $0.6 \mathrm{ml}$ extraction buffer (guanidine thiocyanate, Tris-HCl, EDTA. Triton X-100) was placed in a $1.5-\mathrm{ml}$ centrifuge tube and $200 \mu \mathrm{l}$ blood sample was added; the mixture was incubated for 5-10 min at room temperature with continuous gentle mixing to avoid shock and DNA shearing. The mixture was then centrifuged at $13,000 \mathrm{x} \mathrm{g}$ for $10 \mathrm{~min}$ at room temperature. The supernatant $(0.7 \mathrm{ml})$ was loaded onto a pre-prepared adsorption column (Beijing Solarbio Science \& Technology Co., Ltd., Beijing, China), which was placed in a $1.5-\mathrm{ml}$ collection tube. The column was then centrifuged at $12,000 \mathrm{x} \mathrm{g}$ for $30 \mathrm{sec}$ at room temperature and the eluate was discarded. Subsequently $500 \mu \mathrm{l}$ binding buffer was added to the adsorption column, followed by centrifugation at $12,000 \mathrm{x} \mathrm{g}$ for $30 \mathrm{sec}$ at room temperature. The eluent was discarded and $600 \mu \mathrm{l}$ wash buffer $(70 \%$ ethanol supplemented with $10 \mathrm{mM}$ $\mathrm{NaCl}$ ) was added to the adsorption column, followed by centrifugation at $12,000 \mathrm{x}$ g for $1 \mathrm{~min}$ at room temperature and discarding of the eluent. This washing step was repeated once and the adsorption column was transferred to a fresh $1.5-\mathrm{ml}$ microcentrifuge tube. $50 \mu 1$ Tris-EDTA buffer was added to the column followed by incubation for $1 \mathrm{~min}$ at room temperature. The column was then centrifuged at $12,000 \mathrm{x} g$ for $1 \mathrm{~min}$ at room temperature, and the eluate containing the DNA was collected and stored at $-20^{\circ} \mathrm{C}$.

Primer design. As opposed to ordinary PCR primers, HRMA requires the design of primers for the synthesis of PCR products of $<150 \mathrm{bp}$. PCR products were sequenced using separate sequencing primers; the amplified product of PCR using the sequencing primers was $>300 \mathrm{bp}$. Primers were designed according to the published National center for Biotechnology Information (http://www.ncbi.nlm.nih.gov/) gene sequence for the Tg gene. HRMA primers and sequencing primers for the Tg gene are listed in Table I. Primers were synthesized by Sangon Biotech (Shanghai, China). 
Quantitative PCR conditions and HRMA analysis. Each 20- $\mu 1$ reaction mixture contained $1 \mu 1$ template, $1 \mu 1$ forward primer, $1 \mu 1$ reverse primer, $10 \mu 1$ 10X HS TaqE mix (KangWei Century Biotechnology Company, Beijing, China), $1 \mu 1$ 20X EvaGreen (Biotium, Hayward, CA, USA), and $6 \mu \mathrm{l}$ sterile distilled water. Once mixed, the PCR was performed using a LightCycler 480 RT-PCR machine (Roche Diagnostics, Basel, Switzerland) for fluorescence quantitation. The reaction procedure was performed using the following thermocycling conditions: $95^{\circ} \mathrm{C}$ for $10 \mathrm{~min}$, followed by 40 cycles of $95^{\circ} \mathrm{C}$ for $10 \mathrm{sec}$ and $60^{\circ} \mathrm{C}$ for $15 \mathrm{sec}$, during which fluorescence measurements were collected; then $95^{\circ} \mathrm{C}$ for $10 \mathrm{sec}$ and $65^{\circ} \mathrm{C}$ for $15 \mathrm{sec}$; and finally, the temperature was increased from 60 to $95^{\circ} \mathrm{C}$ in $1^{\circ} \mathrm{C}$-steps A total of 50 fluorescence measurements were collected to obtain the melting curve. After the PCR and high-resolution melting curves were completed, GeneScanning software (Roche Diagnostics) on the LightCycler instrument was used for analysis of high-resolution melting curves. Through software analysis, DNA samples were assigned to three categories: Mutant homozygous, wild-type homozygous or heterozygous. In each category, the PCR products of selected samples were completely sequenced by Sangon Biotech. The gel electrophoresis was performed on $1 \%$ agarose gels (Biowest Agarose; Gene Tech Company, Hong Kong, China). The marker DL2000 (Takara Bio, Inc., Otsu, Japan) was used as the molecular standard.

Statistical analysis. After data from individual samples had been recorded, genotype, allele and haplotype frequencies were calculated. SPSS 16.0 software (SPSS, Chicago, IL, USA) was used for statistical analysis. P-values, odds ratios (OR) and $95 \%$ confidence intervals $(95 \% \mathrm{CI})$ were calculated using the $\chi^{2}$ test.

\section{Results}

PCR products. Following PCR, the amplified PCR products were analyzed by gel electrophoresis. The PCR product of E10SNP24 was $80 \mathrm{bp}$ in length, the PCR product of E10SNP158 was $87 \mathrm{bp}$, the PCR product of E12SNP was $93 \mathrm{bp}$ and the PCR product of E33SNP was 80 bp in length. The electrophoresis results showed bands of the expected sizes (Fig. 1).

HRMA. After the PCR was completed, PCR products were analyzed using HRMA. The EvaGreen fluorescent conjugate only labels double-stranded DNA; therefore, as the temperature increased and the DNA gradually unraveled into single strands during the recording of the melting curve, the fluorescence intensity of the mixture was gradually reduced. The DNA sequences of the different genotypes contained different combinations of nucleotide bases, generating PCR products with different melting points and melting curves. The melting curves from different genotypes, which were homozygous for the wild-type allele, while being heterozygous or homozygous for the mutant allele, are represented in graphical form by different colors (Fig. 2). Therefore, the HRMA was able to distinguish between different genotypes; these genotypes were confirmed by DNA sequencing. As an example, the HRMA results for the exon 10 polymorphism, (E10SNP158 T/C), are

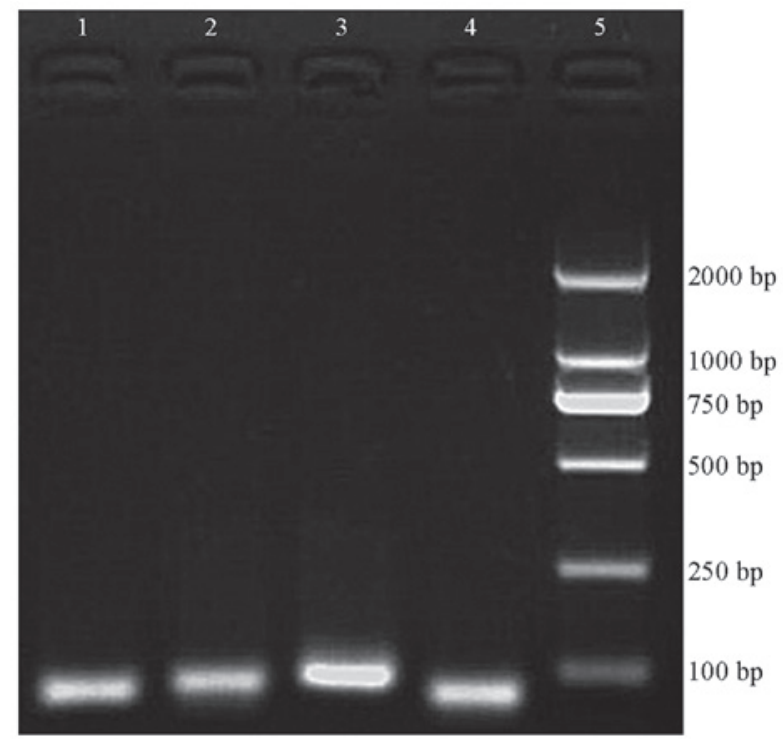

Figure 1. Analysis of PCR reaction products by electrophoresis. Lanes: 1 , 80-bp PCR product of E10SNP24; 2, 87-bp PCR product of E10SNP158; 3, 93-bp PCR product of E12SNP; 4, 80-bp PCR product of E33SNP; 5, 2000-bp DNA maker. PCR, polymerase chain reaction; SNP, single nucleotide polymorphism; E10, exon 10.

shown in Fig. 2; other exon genotype maps were similar to that of the exon 10 SNP158 T/C.

Sequencing results. The HRMA graphs were evaluated via their colored curves displayed in red, blue and green, with each color representing a class of sample genotype. One genotype from each category of samples was selected to be sequenced. Every polymorphic locus of four polymorphic loci had three color curves, and 12 sample curve charts were produced. The PCR products of 12 representative samples were randomly selected to be sequenced, encompassing three exons and four polymorphism loci. The sequencing results provided information regarding the 12 genotypes, consisting of four polymorphic loci which each containing wild-type homozygotes, mutant homozygotes and heterozygotes. Through Tg sequencing, four SNPs were identified: In exon 10, the E10SNP24 T/G allele (GG, TG, and TT genotypes) and the E10SNP158 T/C allele (CC, TC and TT genotypes); in exon 12, the E12SNP A/G allele (AA, AG and GG genotypes); and in exon 33, the E33SNP C/T allele (CC, CT and TT genotypes). Representative sequence diagrams for the E33SNP polymorphism (CC, CT or TT) sequenced diagram are shown in Fig. 3A-C.

Statistical results. The frequency distribution of the E10SNP24 (allele T/G, TG and GG genotypes) and the E12SNP (allele A/G, AG and GG genotypes), was significantly different between patients with AITD and healthy controls $(\mathrm{P}<0.05)$. The OR values of these genotypes showed a strong correlation with the disease. The E10SNP24 GG and TG genotypes, with $\mathrm{OR}=0.14$ for the $\mathrm{GG}$ genotype and $\mathrm{OR}=11.5$ for the TG genotype, and the E12SNP GG and AG genotypes, with $\mathrm{OR}=4.22$ for the $\mathrm{GG}$ genotype and $\mathrm{OR}=0.23$ for the $\mathrm{AG}$ genotype, were highly correlated with the disease. There were no statistically significant differences in the frequency of E10SNP158 and E33SNP polymorphisms when comparing healthy controls 
A

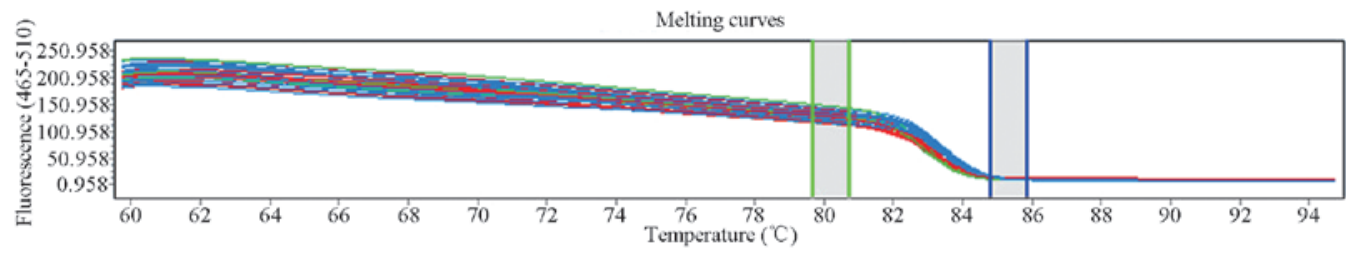

B

Normalized melting curves

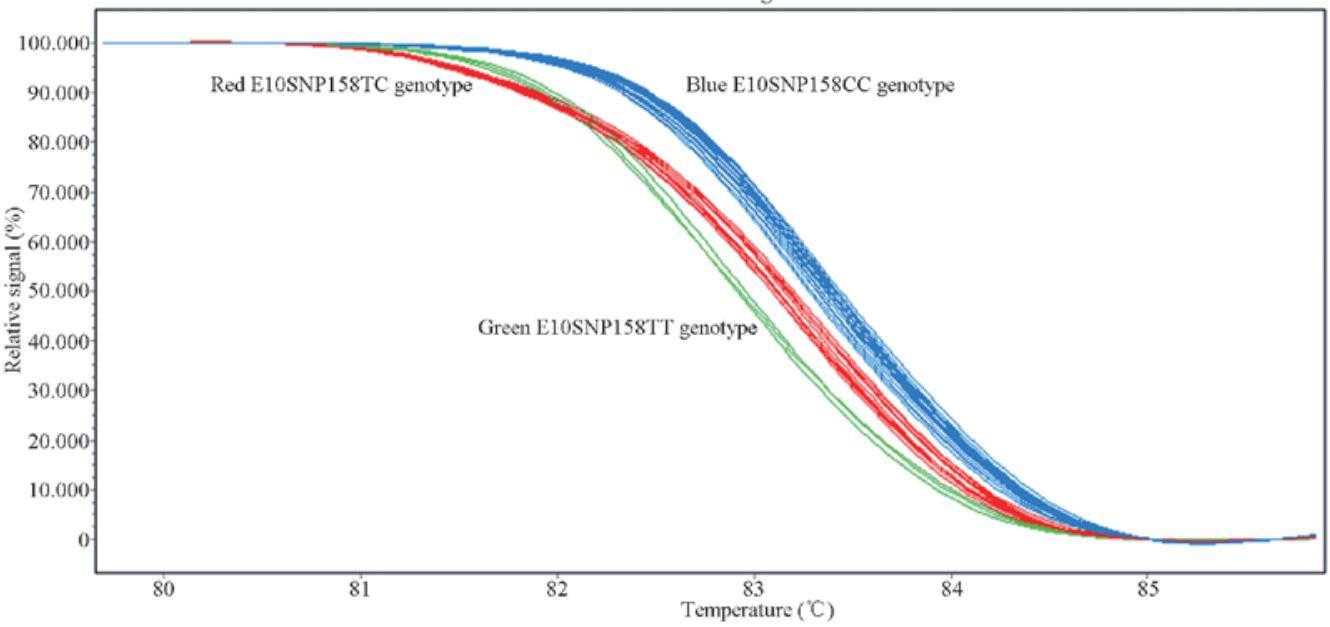

Figure 2.E10SNP158T/C HRMA. E10SNP158T/C includes the polymorphism, its dissolution points are different, therefore the dissolution curves are different. The blue curve indicates the E10SNP158CC genotype, the red curve indicates the E10SNP158TC genotype and the green curve indicates the E10SNP158TT genotype. (A) Thumbnail and (B) enlarged drawing of E10SNP158 HRMA segmentation. SNP, single nucleotide polymorphism; E10, exon 10; HRMA, highresolution melting curve analysis.

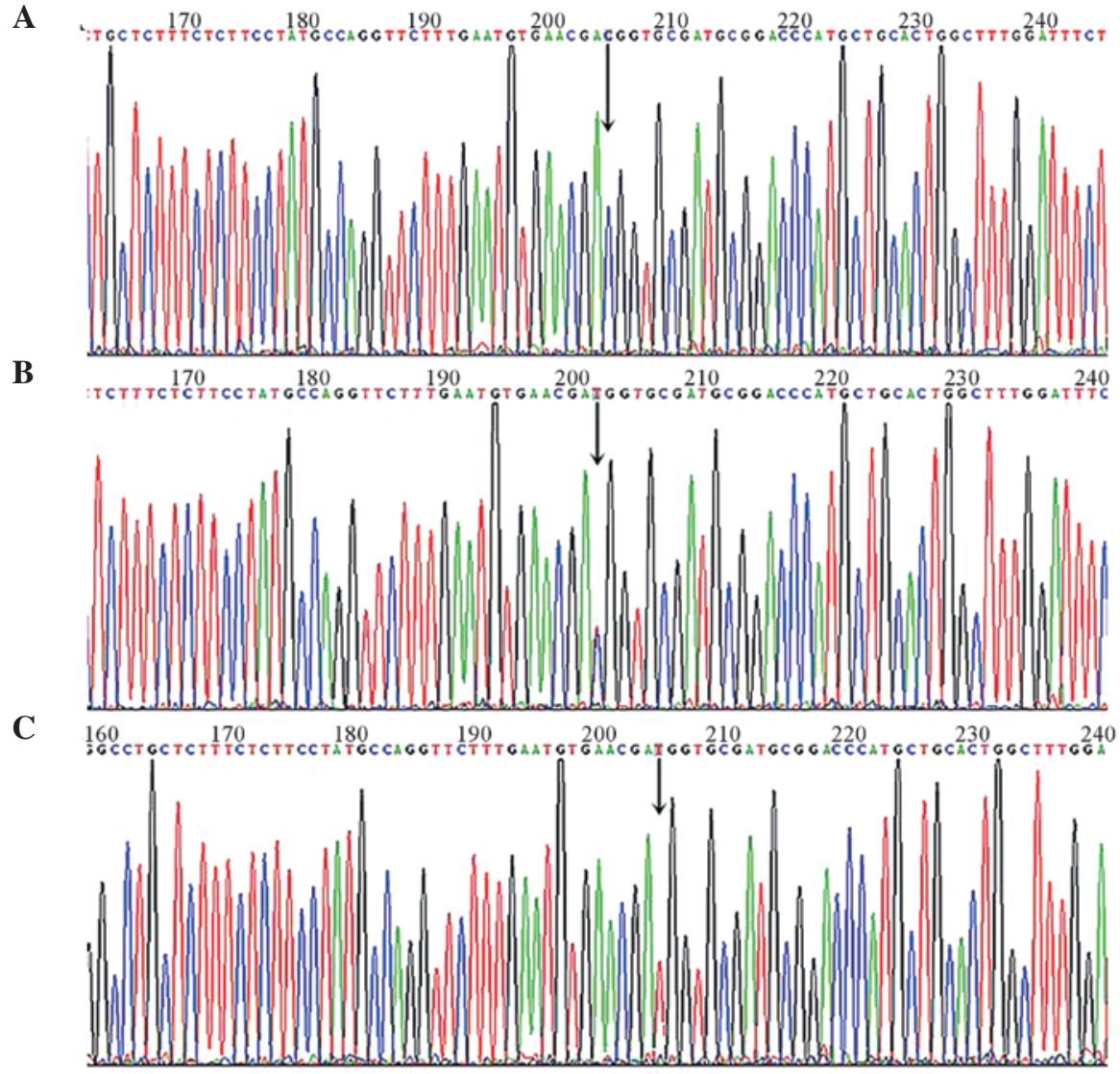

Figure 3. Sequencing analysis. The HRMA graphs were evaluated via their colored curves displayed in red, blue and green, with each color representing a class of sample genotype. One genotype from each category of samples was selected to be sequenced. Every polymorphic locus had three color curves. (A) E33SNP $\mathrm{CC}$ genotype sequencing maps and polymorphic loci. Exon 33 (20 bases) is a polymorphic locus. The arrow indicates a single peak which was proved to be the homozygous CC genotype. (B) E33SNP TC genotype sequencing maps and polymorphic loci. Exon 33 (20 bases) is a polymorphic locus. The arrow indicates a double peak, which was proved to be the heterozygous TC genotype. (C) E33SNP TT genotype sequencing maps and polymorphic loci. Exon 33 (20 bases) is a polymorphic locus, and the arrow indicates a single peak, which was proved to be the homozygous TT genotype. SNP, single nucleotide polymorphism; E33, exon 33 . 
Table II. Frequency distribution of each Tg allele and Tg genotype in subjects with AITD compared with healthy controls [n (\%)].

\begin{tabular}{|c|c|c|c|c|c|c|c|}
\hline SNP & Allele/genotype & AITD & Healthy control & $\chi^{2}$ & P-value & OR & $95 \% \mathrm{CI}$ \\
\hline \multirow[t]{5}{*}{ E10SNP24 } & $\mathrm{T}$ & $120(22.2)$ & $18(6.3)$ & 34.50 & $<0.01$ & 4.29 & $2.55-7.20$ \\
\hline & G & $420(77.8)$ & $270(93.7)$ & 34.50 & $<0.01$ & 4.29 & $2.55-7.20$ \\
\hline & $\mathrm{TT}$ & $15(5.6)$ & $6(4.2)$ & 0.38 & 0.54 & 1.35 & $0.51-3.57$ \\
\hline & TG & $90(33.3)$ & $6(4.2)$ & 44.85 & $<0.01$ & 11.50 & $4.89-27.06$ \\
\hline & GG & $165(61.1)$ & $132(91.6)$ & 43.24 & $<0.01$ & 0.14 & $0.08-0.27$ \\
\hline \multirow[t]{5}{*}{ E10SNP158 } & $\mathrm{T}$ & $117(21.7)$ & $63(21.9)$ & 0.01 & 0.95 & 0.99 & $0.70-1.40$ \\
\hline & $\mathrm{C}$ & $423(78.3)$ & $225(78.1)$ & 0.01 & 0.95 & 0.99 & $0.70-1.40$ \\
\hline & $\mathrm{TT}$ & $12(4.5)$ & $6(4.2)$ & 0.02 & 0.90 & 1.07 & $0.39-2.91$ \\
\hline & $\mathrm{TC}$ & $93(34.4)$ & $51(35.4)$ & 0.04 & 0.84 & 0.96 & $0.63-1.46$ \\
\hline & $\mathrm{CC}$ & 165 (61.1) & 87 (60.4) & 0.02 & 0.89 & 1.03 & $0.68-1.56$ \\
\hline \multirow[t]{5}{*}{ E12SNP } & A & $54(10.0)$ & $75(26.0)$ & 36.61 & $<0.01$ & 0.32 & $0.22-0.47$ \\
\hline & G & $486(90.0)$ & $213(74.0)$ & 36.61 & $<0.01$ & 0.32 & $0.22-0.47$ \\
\hline & AA & $12(4.4)$ & $12(8.3)$ & 2.60 & 0.11 & 0.51 & $0.22-1.17$ \\
\hline & $\mathrm{AG}$ & $30(11.1)$ & $51(35.4)$ & 35.25 & $<0.01$ & 0.23 & $0.14-0.38$ \\
\hline & GG & $228(84.4)$ & $81(56.3)$ & 39.44 & $<0.01$ & 4.22 & $2.65-6.73$ \\
\hline \multirow[t]{5}{*}{ E33SNP } & $\mathrm{C}$ & 489 (90.6) & $258(89.6)$ & 0.20 & 0.65 & 1.12 & $0.69-1.79$ \\
\hline & $\mathrm{T}$ & $51(9.4)$ & $30(10.4)$ & 0.20 & 0.65 & 1.12 & $0.69-1.79$ \\
\hline & $\mathrm{CC}$ & $234(86.7)$ & $123(85.4)$ & 0.12 & 0.73 & 1.11 & $0.62-1.98$ \\
\hline & $\mathrm{CT}$ & $21(7.8)$ & $12(8.3)$ & 0.04 & 0.84 & 0.93 & $0.44-1.94$ \\
\hline & $\mathrm{TT}$ & $15(5.5)$ & $9(6.3)$ & 0.08 & 0.77 & 0.88 & $0.38-2.07$ \\
\hline
\end{tabular}

Tg, thyroglobulin; OR, odds ratio; CI, confidence interval; SNP, single nucleotide polymorphism; AITD autoimmune thyroid disease; E10, exon 10.

Table III. Tg haplotype gene SNP portfolio analysis of the frequency between the disease and healthy control groups [n (\%)].

\begin{tabular}{|c|c|c|c|c|c|c|c|}
\hline $\begin{array}{l}\text { E10 } \\
\text { SNP } \\
24\end{array}$ & $\begin{array}{c}\text { E10 } \\
\text { SNP } \\
158\end{array}$ & $\begin{array}{l}\text { E12 } \\
\text { SNP }\end{array}$ & $\begin{array}{l}\text { E33 } \\
\text { SNP }\end{array}$ & $\begin{array}{l}\text { Hypothyroidism } \\
\qquad(\mathrm{n}=81)\end{array}$ & $\begin{array}{c}\text { Graves' } \\
\text { disease } \\
(n=78)\end{array}$ & $\begin{array}{c}\mathrm{HT} \\
(\mathrm{n}=111)\end{array}$ & $\begin{array}{l}\text { Healthy control } \\
\qquad(\mathrm{n}=144)\end{array}$ \\
\hline $\mathrm{G}$ & $\mathrm{C}$ & G & $\mathrm{C}$ & $27(33.3)$ & $30(38.5)$ & $36(32.4)^{\mathrm{a}}$ & $66(45.8)$ \\
\hline G & $\mathrm{C}$ & A & $\mathrm{C}$ & $6(7.4)$ & $6(7.7)$ & $6(5.4)$ & $9(6.3)$ \\
\hline G & $\mathrm{T}$ & A & $\mathrm{C}$ & $6(7.4)^{\mathrm{b}}$ & $6(7.7)^{b}$ & $9(8.1)^{b}$ & $39(27.1)$ \\
\hline G & $\mathrm{T}$ & $\mathrm{G}$ & $\mathrm{C}$ & $9(11.1)$ & $15(19.2)^{\mathrm{b}}$ & $21(18.9)^{b}$ & $9(6.3)$ \\
\hline $\mathrm{T}$ & $\mathrm{T}$ & $\mathrm{G}$ & $\mathrm{C}$ & $12(14.9)^{\mathrm{b}}$ & $6(7.7)$ & $15(13.5)$ & $6(4.2)$ \\
\hline $\mathrm{T}$ & $\mathrm{C}$ & A & $\mathrm{C}$ & $6(7.4)$ & $6(7.7)$ & $6(5.4)$ & $9(6.3)$ \\
\hline $\mathrm{T}$ & $\mathrm{C}$ & $\mathrm{G}$ & $\mathrm{C}$ & $15(18.5)^{b}$ & $9(11.5)^{\mathrm{a}}$ & $18(16.2)^{b}$ & $6(4.2)$ \\
\hline
\end{tabular}

Analysis of haploid allele combinations were compared between the disease group and the healthy group. ${ }^{\mathrm{a}} \mathrm{P}<0.01$, ${ }^{\mathrm{b}} \mathrm{P}<0.05$, disease group vs healthy control group. Hypothyroidism (G-T-A-C, OR=0.22; T-T-G-C, OR=4.00; T-C-G-C, OR=5.23); Graves (G-T-A-C, OR=0.22; G-T-G-C, OR=3.57; T-C-G-C, OR=3.00); HT (G-C-G-C, OR=0.57; G-T-A-C, OR=0.24; G-T-G-C, OR=3.50; G-T-G-C, OR=3.59; T-C-G-C, $\mathrm{OR}=4.45$ ). HT, haplotype; Tg, thyroglobulin; OR, odds ratio; SNP, single nucleotide polymorphism; E10, exon 10.

with AITD patients ( $\mathrm{P}>0.05)$ (Table II). Furthermore, a haplotype analysis of the four Tg polymorphic loci, E10SNP24, E10SNP158, E12SNP and E33SNP, was performed. There were seven haplotype combinations of gene polymorphisms that occurred more frequently in AITD patients than in healthy controls, and among these, five haplotype combinations were significantly different (Table III).

The haplotype combination of gene polymorphisms was not significantly different between the different disease sub-groups $(\mathrm{P}>0.05)$. Certain gene polymorphism combinations were most likely to occur more frequently amongst AITD patient groups: Disease-linked haplotypes (denoted as E10SNP24 - E10SNP158 - E12SNP - E33SNP) were present in the primary hypothyroidism group (G-T-A-C, T-T-G-C and T-C-G-C), the hyperthyroidism group (G-T-A-C, G-T-G-C and T-C-G-C) and the Hashimoto's disease group (G-C-G-C, G-T-A-C, G-T-G-C and T-C-G-C); compared with those in the healthy controls, these haplotypes were significantly different 
Table IV. Comparison of the frequency of the thyroglobulin exon 33 single-nucleotide polymorphism between healthy Han people in North Henan with those in the Xi'an region of Shaanxi $[\mathrm{n}(\%)]$.

\begin{tabular}{lccrr}
\hline Allele/genotype & North Henan (HRMA) & Xi'an (RFLP) & $X^{2}$ & P-value \\
\hline C & $258(89.6)$ & $163(76.9)$ & 14.797 & $<0.001$ \\
T & $30(10.4)$ & $49(23.1)$ & 14.797 & $<0.001$ \\
CC & $123(85.4)$ & $65(61.3)$ & 19.008 & $<0.001$ \\
CT & $12(8.3)$ & $33(31.1)$ & 21.501 & $<0.001$ \\
TT & $9(6.3)$ & $8(7.5)$ & 0.162 & 0.687 \\
\hline
\end{tabular}

HRM, high-resolution melting curve analysis; RFLP, restriction fragment length polymorphism. Xi'an data were published previously (25).

$(\mathrm{P}<0.05)$. The odds ratios for these haplotypes showed various degrees of association with the disease (Table III).

The present study also compared the E33SNP of the Tg gene between the healthy Han population from the Northern regions of Henan province with those from a population from the Xi'an region of Shaanxi province. Results of the statistical analysis of these two Han populations are shown in Table IV. Xi'an data were published previously The present study used HRMA to assess the Tg gene E33SNP in a Han population from Northern Henan, showing that the $\mathrm{C}$ allele frequency in the Tg exon 33 SNP was $89.6 \%$, and the locus was dominated by the CC genotype with a frequency of $85.4 \%$.

\section{Discussion}

Thyroglobulin is not only a major protein component of thyroid tissue, but also one of the major AITD autoantigens. Tg has an important role in the pathogenesis of AITD $(24,25)$. The $\mathrm{Tg}$ gene is a susceptibility gene for AITD (3-5), and SNPs in the Tg gene were correlated with AITD in animals and humans (3-5). The present study used the HRMA method to detect Tg SNPs; the HRMA method is simple, accurate, economical, rapid, high-throughput, and can be widely used for the detection of disease-associated gene SNPs and mutations. The HRMA method uses fluorescent probes to examine the differing dissolution profiles of PCR products of different genotypes, based on the different base pairing in homozygous and heterozygous sequences, leading to different melting curves from low to high temperatures, thereby easily distinguishing alleles by detecting a change in the fluorescence signal (15).

The present study found four alleles in the $\mathrm{Tg}$ gene in a Han Chinese population, as well as twelve associated genotypes; the distribution frequencies of E10SNP24 (TG and GG genotypes) and E12SNP (AG and GG genotypes) were significantly different between patients with AITD and healthy controls. Haplotype allele combinations in the primary hypothyroidism group (including G-T-A-C, T-T-G-C and T-C-G-C), hyperthyroidism group (including G-T-A-C, G-T-G-C and T-C-G-C) and Hashimoto's disease group (including G-C-G-C, G-T-A-C, G-T-G-C and T-C-G-C) were significantly correlated with the disease. These alleles, genotypes and haplotype combinations of alleles showed a strong correlation with AITD. However, combinations of haploid genes between disease groups were not significantly different.

The results of the present study are not in line with the results of a study by Zhang et al (26), who found that the differences in distribution of allele frequencies between AITD cases and healthy controls were not statistically significant, and that the only haplotype correlation was between the G-C-A-C haplotype and Hashimoto's disease. By contrast, the present study identified nine haplotypes to be correlated with various forms of AITD. The results of the present study may differ from those of Zhang et al (26), who used the PCR-restriction fragment length polymorphism (RFLP) method, due to a different experimental approach, or the existence of regional differences in the population; the specific reasons require to be confirmed in further studies. The present study utilized the HRMA method for detecting Tg gene SNPs and studied Tg exon SNPs in a Han Chinese population from the Northern region of Henan. In this population, the presence of E10SNP24 T/G, E10SNP158 T/C, E12SNP A/G and E33SNP C/T was confirmed, consistent with the study by Zhang et al (26). The present study showed that the C-allele frequency in the Tg exon 33 SNP was $89.6 \%$ in the study population, and the locus was dominated by the CC genotype with a frequency of $85.4 \%$. The CC and CT genotypes in the E33SNP showed statistically significant differences in the distribution of frequencies $(\mathrm{P}<0.05)$, the TT genotype was not significantly different between groups $(\mathrm{P}>0.05)$. By contrast, a C-allele frequency of $76.9 \%$ and a CC-genotype frequency of $61.3 \%$ were reported by Zhang et al (26). Prior to the present study, a preliminary study performed by our group confirmed the existing regional distribution of SNP frequencies in the $\mathrm{Tg}$ gene of a Chinese Han population. The frequency of the TG exon 33 SNP C allele was reported to be $53.9 \%$ in Caucasians, with a TC genotype frequency of $>45 \%$ (5); these data further confirm the differing gene polymorphism frequencies in different regions and ethnic groups.

In conclusion, the present study provided molecular evidence at the DNA level to link Tg polymorphisms with AITD.

\section{Acknowledgements}

The present study was supported by a grant from the National Natural Science Foundation of China (grant no. 31371332). 


\section{References}

1. Zhang MX and Wu YQ (eds): The Diagnosis and Treatment of Thyroid Disease. 1st edition. Pharmaceutical Science and Technology Publishing House, Beijing, pp38-42, 2006 (In Chinese).

2. Tomer Y and Davies TF: Searching for the autoimmune thyroid disease susceptibility genes: From gene mapping to gene function. Endocr Rev 24: 694-717, 2003.

3. Ban Y, Greenberg DA, Concepcion E, Skrabanek L, Villanueva R and Tomer Y: Amino acid substitutions in the thyroglobulin gene are associated with susceptibility to human and murine autoimmune thyroid disease. Proc Natl Acad Sci USA 100: $15119-15124,2003$.

4. Ban Y, Tozaki T, Taniyama M, Tomita M and Ban Y: Association of a thyroglobulin gene polymorphism with Hashimoto's thyroiditis in the Japanese population. Clin Endocrinol (Oxf) 61: 263-268, 2004.

5. Collins JE, Heward JM, Howson JM, Foxall H, Carr-Smith J, Franklyn JA and Gough SC: Common allelic variants of exons 10,12 and 33 of the thyroglobulin gene are not associated with autoimmune thyroid disease in the United Kingdom. J Clin Endocrinol Metab 89: 6336-6339, 2004.

6. Orita M, lwahana H, Kanazawa H, Hayashi K and Sekiya T: Detection of polymorphisms of human DNA by gel electrophoresis as single-strand conformation polymorphisms. Proc Natl Acad Sci USA 86: 2766-2770, 1989

7. Lerman LS and Silverstein K: Computational simulation of DNA melting and its application to denaturing gradient gel electrophoresis. Methods Enzymol 155: 482-501, 1987.

8. Xiao W and Oefner PJ: Denaturing high-performance liquid chromatography: A review. Hum Mutat 17: 439-474, 2001.

9. Li Q, Liu Z, Monroe H and Culiat CT: Integrated platform for detection of DNA sequence variants using capillary array electrophoresis. Electrophoresis 23: 1499-1511, 2002.

10. Böcker S: Simulating multiplexed SNP discovery rates using base-specific cleavage and mass spectrometry. Bioinformatics 23 : e5-e12, 2007.

11. Liao Y, Wang X, Sha C, Xia Z, Huang Q and Li Q: Combination of fluorescence color and melting temperature as a two-dimensional label for homogeneous multiplex PCR detection. Nucleic Acids Res 41: e76, 2013.

12. Wang CZ, Lin J, Qian J, Shao R, Xue D, Qian W, Xiao GF, Deng ZQ, Yang J, Li Y, et al: Development of high-resolution melting analysis for the detection of the MYD88 L265P mutation. Clin Biochem 46: 385-387, 2013.

13. Tindall EA, Petersen DC, Woodbridge P, Schipany K and Hayes VM: Assessing high-resolution melt curve analysis for accurate detection of gene variants in complex DNA fragments. Hum Mutat 30: 876-883, 2009.
14. Pang Y, Zhou Y, Wang S, Lu J, Lu B, He G, Wang L and Zhao Y: A novel method based on high resolution melting (HRM) analysis for MIRU-VNTR genotyping of Mycobacterium tuberculosis. J Microbiol Methods 86: 291-297, 2011.

15. Vossen RH, Aten E, Roos A and den Dunnen JT: High-resolution melting analysis (HRMA): More than just sequence variant screening. Hum Mutat 30: 860-866, 2009.

16. de Juan Jiménez I, Cardeñosa EE, Suela SP, González EB, Trejo DS, Lluch OF and Gilabert PB: Advantage of high-resolution melting curve analysis over conformation-sensitive gel electrophoresis for mutational screening of BRCA1 and BRCA2 genes. Clin Chim Acta 412: 578-582, 2011.

17. Minucci A, Canu G, Gentile L, Zuppi C, Giardina B and Capoluongo E: Small amplicons high resolution melting analysis (SA-HRMA) allows successful genotyping of acid phosphatase 1 (ACP1) polymorphisms in the Italian population. Clin Chim Acta 416: 86-91, 2013.

18. Liu SM, Xu FX, Shen F and Xie Y: Rapid genotyping of APOA5-1131T $>$ C polymorphism using high resolution melting analysis with unlabeled probes. Gene 498: 276-279, 2012.

19. Zhou L, Errigo RJ, Lu H, Poritz MA, Seipp MT and Wittwer CT: Snapback primer genotyping with saturating DNA dye and melting analysis. Clin Chem 54: 1648-1656, 2008.

20. Martín-Núñez GM, Gómez-Zumaquero JM, Soriguer F and Morcillo S: High resolution melting curve analysis of DNA samples isolated by different DNA extraction methods. Clin Chem Acta 413: 331-333, 2012.

21. Rajaei M, Saadat I and Saadat M: High resolution melting analysis for detection of variable number of tandem repeats polymorphism of XRCC5. Biochem Biophys Res Commun 425: 398-400, 2012.

22. Wang TY, Wang L, Zhang JH and Dong WH: A simplified universal genomic DNA extraction protocol suitable for PCR. Genet Mol Res 10: 519-525, 2011.

23. Orgiazzi J: Autoimmune thyroid diseases, an overview. Rev Prat 64: 822-824, 2014 (In French).

24. Okosieme OE, Parkes AB, Premawardhana LD, Evans C and Lazarus JH: Thyroglobulin: Current aspects of its role in autoimmune thyroid disease and thyroid cancer. Minerva Med 94: 319-330, 2003.

25. Okosieme OE, Premawardhana LD, Jayasinghe A Kaluarachi WN, Parkes AB, Smyth PP, Lejeune PJ, Ruf J and Lazarus JH: Thyroglobulin autoantibodies in iodized subjects: relationship between epitope specificities and longitudinal antibody activity. Thyroid 15: 1067-1072, 2005.

26. Zhang JA, Maier-Haba, Yu ZY, Xiao WX and Wang Y: Association of thyroglobulin gene polymorphisms with autoimmune thyroid diseases. J Fouth Mil Med Univ 27: 1748, 2006 (In Chinese). 